\title{
A whale alarm fails to deter migrating humpback whales: an empirical test
}

\author{
Robert Harcourt ${ }^{1, *}$, Vanessa Pirotta ${ }^{1}$, Gillian Heller ${ }^{2}$, Victor Peddemors ${ }^{3}$, \\ David Slip ${ }^{1,4}$
}

\author{
${ }^{1}$ Department of Biological Sciences, Macquarie University, Sydney, NSW 2109, Australia \\ ${ }^{2}$ Department of Statistics, Macquarie University, Sydney, NSW 2109, Australia \\ ${ }^{3}$ Fisheries NSW, Sydney Institute of Marine Science, Sydney, NSW 2088, Australia \\ ${ }^{4}$ Taronga Conservation Society Australia, Sydney, NSW 2088, Australia
}

\begin{abstract}
Cetacean entanglements in fishing gear cost governments, fishermen and stakeholders millions of dollars a year, and often result in serious injury or death of the entangled animals. Entanglements have been implicated in preventing the recovery of some large whale populations. Acoustic deterrents on fishing nets are widely used to reduce incidental captures of dolphins and porpoises, but there is little evidence as to whether they effectively deter large whales. We tested whether a low-frequency whale alarm ( $3 \mathrm{kHz}$ Whale Pinger ${ }^{\circledR}, 135 \pm 5 \mathrm{db}, 5 \mathrm{~s}$ emission interval and 400 ms emission duration) deterred Southern Hemisphere humpback whales Megaptera novaeangliae from approaching a potential source of entanglement. Northerly migrating humpback whale pods were tracked by an observer blind to alarm status (on/off) as they passed an alarm moored in the centre of the peak migration path. Of 137 pods tracked, $82(60 \%)$ passed within the assumed detectable range $(500 \mathrm{~m})$ of the alarm, 51/78 (65\%) when it was on and $31 / 59(52 \%)$ when it was off $(p=0.18)$. There was no discernible response to the alarm. Whale pods did not differ in directionality, course heading or dive duration when within detectable range of the alarm, whether it was on or off, and a number of pods passed directly over the alarm while it was operational. This suggests that single alarms as currently configured and attached to a trap or pot line are unlikely to effectively deter humpback whales from approaching potential hazards, at least during their northerly migration phase.
\end{abstract}

KEY WORDS: Fisheries entanglement $\cdot$ Mortality $\cdot$ Bycatch $\cdot$ Acoustic deterrents $\cdot$ Megaptera novaeangliae Resale or republication not permitted without written consent of the publisher

\section{INTRODUCTION}

Many (though not all) baleen whale populations around the world are recovering following severe exploitation during the industrial whaling era, and this recovery has been well documented in particular for coastal species such as humpback Megaptera novaenageliae (Gales et al. 2011, Harcourt et al. in press), gray Eschrichtius robustus (Bradford et al. 2008, Weller et al. 2013) and southern right whales Eubalaena australis (IWC 2011, also reviewed by Lotze et al. 2011, Magera et al. 2013). At the same time, capture fisheries for finfish, elasmobranchs and invertebrates have either expanded or remained at high intensities in most oceans of the world (Pauly et al. 2005). As populations of whales grow, their chances of encountering either nets or lines are also increased, and entanglement in fishing gear has been identified as a leading cause of mortality for some whale species (Moore 2014), to the extent that in some cases it is believed to be inhibiting population recovery (Knowlton et al. 2012). Globally, entanglements appear to be increasing (Meÿer et al. 2011, Groom \& Coughran 2012). Moreover, the impacts of entanglement on in- 
dividuals can be severe, ranging from drowning or starvation due to impaired foraging, lacerations, amputations and other serious injuries, to systemic infections following injury. Besides its impacts on populations, entanglement represents a major animal welfare issue (Cassoff et al. 2011, Moore \& van der Hoop 2012).

Baleen whale interactions with fishing gear off Newfoundland, Canada, in the early 1970s led to the development of simple sound-producing devices intended to warn whales away from the nets (Lien et al. 1992). This technology has been further developed over recent years, and at least in some areas (e.g. Australia; Alaska, USA), fisheries have been allowed to fish in areas of high whale abundance as long as they deploy whale alarms on their gear. In Australia, this includes the 2 extensive shark beach meshing operations (Queensland and New South Wales; Reid et al. 2011) that are known to entrap whales (Green et al. 2009). Acoustic deterrents have been deployed with mixed success to deter phocoenids, delphinids and other cetaceans from a variety of fisheries gear (Dawson et al. 2013). Surprisingly, no systematic trials have been conducted in situ with whales and whale alarms to determine the efficacy of these devices in reducing whale interactions with fishing gear (Jefferson \& Curry 1996), although there have been a number of studies of the propagation of alarm signals (McPherson 2011).

East Australian humpback whales (E1 breeding stock, Gales et al. 2011) use the east coast of Australia each year as a migratory corridor to travel between their high-latitude feeding grounds and their low-latitude breeding grounds (Chittleborough 1965, Vang 2002, Gales et al. 2011). Commercial exploitation of the species during the mid- $20^{\text {th }}$ century saw a dramatic decline in the population, with the population estimated to have reached as low as a few hundred animals by the end of whaling (Chittleborough 1965, Paterson et al. 1994). Currently, the population is recovering at almost maximum capacity of $10.9 \%$ per annum, with a population estimate for 2010 of 14522 whales $(95 \%$ CI 12777-16 504) (Noad et al. 2011, Harcourt et al. in press). They remain listed as 'vulnerable' under the Environment Protection and Biodiversity Conservation Act 1999 (EPBC Act). The tendency for this population to migrate within $15 \mathrm{~km}$ of the shore leads to increased potential for interaction with fishing gear. This will inevitably intensify as the population grows with continued protection from whaling, potentially leading to fisheries entanglement becoming the largest modern-day anthropogenic threat to the recovery of the population.
Here we aimed to test the efficacy of low-frequency whale alarms as a deterrent to large cetaceans swimming into and becoming entangled in nets and set lines. Large numbers of humpback whales travelling north on their winter migration pass within $10 \mathrm{~km}$ of shore each June and July, providing a unique opportunity to assess the responses of multiple individuals in a relatively short period of time. We tested the efficacy of a low-frequency whale alarm in deterring humpback whales from approaching a potential source of entanglement (a mooring, functionally equivalent to a lobster pot mooring) centred within their migratory corridor.

\section{MATERIALS AND METHODS}

\section{Study site}

This study was conducted at Cape Solander in Botany Bay National Park, Sydney, Australia (34 $01^{\prime} \mathrm{S}$, $\left.151^{\circ} 14^{\prime} \mathrm{E}\right)$. Cape Solander is located at the southern headland of Botany Bay and provides an uninterrupted view over the study area, and is the site of a long-term study to monitor the number of humpback whales migrating north along the New South Wales coast each winter since 1997 (Gulesserian et al. 2011)

\section{Whale alarm}

We installed a fixed mooring $1.3 \mathrm{~km}$ offshore of the observation platform in $53 \mathrm{~m}$ of water and attached a commercially available whale alarm, the Fumunda F3, $3 \mathrm{kHz}$ Whale Pinger ${ }^{\circledR}(135 \pm 5$ db, 5 s emission interval, $400 \mathrm{~ms}$ emission duration) at a depth of $5 \mathrm{~m}$. Note that although the output level specified by the manufacturer is $135 \mathrm{~dB}$ re $1 \mu \mathrm{Pa}$, Erbe et al. (2011) found that, on average, levels were less (98 \pm 7 up to $118 \pm 3 \mathrm{~dB}$ re $1 \mu \mathrm{Pa}^{2} / \mathrm{Hz} @ 1 \mathrm{~m}$ for the fundamentals of $3 \mathrm{~F} 3$ whale alarms tested). This $5 \mathrm{~m}$ depth is similar to that used by Erbe \& McPherson (2012) in their modelling of acoustic characteristics of these whale alarms. Previous research undertaken at Cape Solander suggested that about $90 \%$ of migrating humpback whales should pass between 1.5 and $10 \mathrm{~km}$ of the coast. The whale alarm mooring was therefore anchored in the midpoint of the peak migration route recorded in the years 2006 to 2008 (Gulesserian et al. 2011).

The whale alarm was turned on for a total of $18 \mathrm{~d}$ and off for a total of $16 \mathrm{~d}$ during the northern migra- 
tion of humpback whales. The alarm was changed by free divers in the water and its status (on/off) was confirmed audibly in situ. Observers who were tracking the whale paths did not know the status of the alarm on any given day.

\section{Data collection}

We collected data between 1 June and 10 August 2012, coincident with the peak of the northern migration (Vang 2002, Gulesserian et al. 2011). At least 2 people constantly scanned to the south for approaching pods. A pod was defined as 1 or more whales. Once a pod was seen, a focal animal, distinguishable by natural variation in markings and dorsal fin shape, was chosen to track within a pod. Every surface event was recorded for the focal animal as well as surface behaviour from the moment the animal was first sighted until it left the study area (>4000 m north of the observation point) or visibility was hindered. Pods were randomly selected and tracks were recorded using a Sokkia DT510A theodolite with a precision of $\pm 5 \mathrm{~s}$ of $\operatorname{arc}$ and $30 \times$ magnification. The theodolite was set at $1.5 \mathrm{~m}$ high and placed on the Cape Solander observation deck $30.75 \mathrm{~m}$ above sea level. The theodolite was connected to a laptop computer running the custom written software VADAR ${ }^{\circledR}$ (Version 1.51.02, Eric Kneist, University of Newcastle, Australia), and simultaneously measured horizontal and vertical angles to a target that was measured from a known reference object, Cape Banks (the headland north of the field site).

All whales that passed through the study site were on their annual northern migration and so it was assumed that pods passed the observation area only once, ensuring each observation was independent (see Gulesserian et al. 2011). Observations took place from dawn till dusk (subject to daylight, usually from 06:20 to 17:20 h), dependent on weather conditions. Observations were restricted to no rain and Beaufort sea state of $<5$, as it was too difficult to identify and track pods when it was raining or in higher Beaufort conditions.

\section{Determining effective audible range of the whale alarm}

In order to determine the approximate range of the Fumunda F3, 3 kHz Whale Pinger ${ }^{\circledR}$, we used a hydrophone to record alarm output at the mooring site (Cape Solander), and in calm water off the Cronulla
Fisheries Research Centre wharf, Gunnamatta Bay, Australia (34 $\left.{ }^{\circ} 03^{\prime} \mathrm{S}, 151^{\circ} 03^{\prime} \mathrm{E}\right)$. At Cape Solander, we recorded in situ measurements of the acoustic propagation of the whale alarm tones across a grid formation centred on the mooring. Recordings were made at 15 and $5 \mathrm{~m}$ depths using an HTI 554036 hydrophone directly onto an M-Audio Micro Track 24/96 Professional 2-Channel Mobile Digital Recorder, from a boat drifting with wind and current in a systematic fashion along $1000 \mathrm{~m}$ transect lines. A Garmin GPSMAP ${ }^{\circledR} 78 \mathrm{sc}$ GPS was used to locate the start of each transect line based on wind conditions. Once recordings commenced, the boat was left to drift along the entire transect with the drift pattern being continually monitored. Recordings ceased once the boat had reached the end of the transect line. The boat then motored up to the start of the new transect and the recording process was repeated. At Gunnamatta Bay, recordings were taken at 200, 150, 100, 50 and $1 \mathrm{~m}$ away from the alarm, in calm weather conditions (Beaufort 1) at $2 \mathrm{~m}$ depth. The alarm tone was inaudible to humans and no longer detectable on the sonogram $300 \mathrm{~m}$ from the alarm.

Anatomical evidence suggests that baleen whales are adapted to low-frequency ( $7 \mathrm{~Hz}$ to $22 \mathrm{kHz}$ ) hearing (Ketten 1997). Further, ambient noise in the ocean is likely to have played an evolutionary role in shaping baleen whale hearing such that the dynamic range of their auditory systems can be used most efficiently, and so they probably have excellent hearing range at low frequencies (Clark \& Ellison 2004).

Given this, and that Erbe \& McPherson (2012) measured the detectability range of the second harmonic of these alarms to be $210 \mathrm{~m}$ for humpback whales (with background ambient noise off the Gold Coast, farther north in eastern Australia), we assumed that the whales may be able to detect the alarm up to $500 \mathrm{~m}$ away but that it is unlikely that they would detect it at $1000 \mathrm{~m}$.

\section{Data extraction and analysis}

All observational information, including the exact time of each surfacing and behaviour $( \pm 0.5 \mathrm{~s})$, was recorded and exported directly by $\operatorname{VADAR}^{\circledR}$. This included all tracks, track line summaries, observation information and raw observations for every day and every pod.

To be included in the analysis, a pod's path had to include the following:

(1) The track had to last a minimum of $15 \mathrm{~min}$. 
(2) The track had to include multiple (2 or more) dives.

(3) The projected path measured 1500 to $1000 \mathrm{~m}$ south of the alarm would, if continued, pass within $500 \mathrm{~m}$ of the alarm if the pod did not change direction.

Because the whales were moving north at the time, their course varied between $320^{\circ}$ and $40^{\circ}$. We measured the bearing between consecutive surfacings to determine changes in direction of whale movement (course change). Speed was measured as the time (in seconds) taken to traverse the distance (in metres) between consecutive sightings $\left(\mathrm{m} \mathrm{s}^{-1}\right)$

To assess the potential impact of the alarm, we compared the behaviour of whales when they were within likely hearing range of the alarm $(500 \mathrm{~m})$ to the behaviour of the same whales when they were likely to be out of range of the alarm, both when approaching it and when continuing on from it. We assumed that when the whales were 1000 to $1500 \mathrm{~m}$ away from the alarm they were out of the audible range. To test for differences among the 3 groups ('approaching', 'within range', 'leaving'), we used mixed linear models with whale as the subject effect and the response variables course, course change, time between surfacing and speed. Tracks were filtered to remove speeds $>30 \mathrm{~km} \mathrm{~h}^{-1}\left(8.3 \mathrm{~m} \mathrm{~s}^{-1}\right)$. For all statistical analyses, the null hypothesis was rejected if $\mathrm{p}<0.05$. All statistical analyses were performed using the statistical package SPSS 20.0 for Windows.

\section{RESULTS}

In total, we collected 137 tracks over $430 \mathrm{~h}$, of which $82(60 \%)$ passed within $500 \mathrm{~m}$ of the alarm. Of these, $31(38 \%)$ tracks were recorded when the alarm was off and 51 (62\%) tracks were recorded when the alarm was on ( $p=0.18$; Table 1$)$. Visually, the tracks when the alarm was off were not discernible from those when the alarm was on (Fig. 1a,b).

Table 1. Total number of humpback whale Megaptera novaeangliae tracks that passed inside and outside the $500 \mathrm{~m}$ radius of the likely detection zone when the alarm was on and when it was off

\begin{tabular}{|lcccc|}
\hline & On & Off & Total & $\%$ \\
\hline Inside & 51 & 31 & 82 & 60 \\
Outside & 27 & 28 & 55 & 40 \\
Total & 78 & 59 & 137 & 100 \\
\hline
\end{tabular}

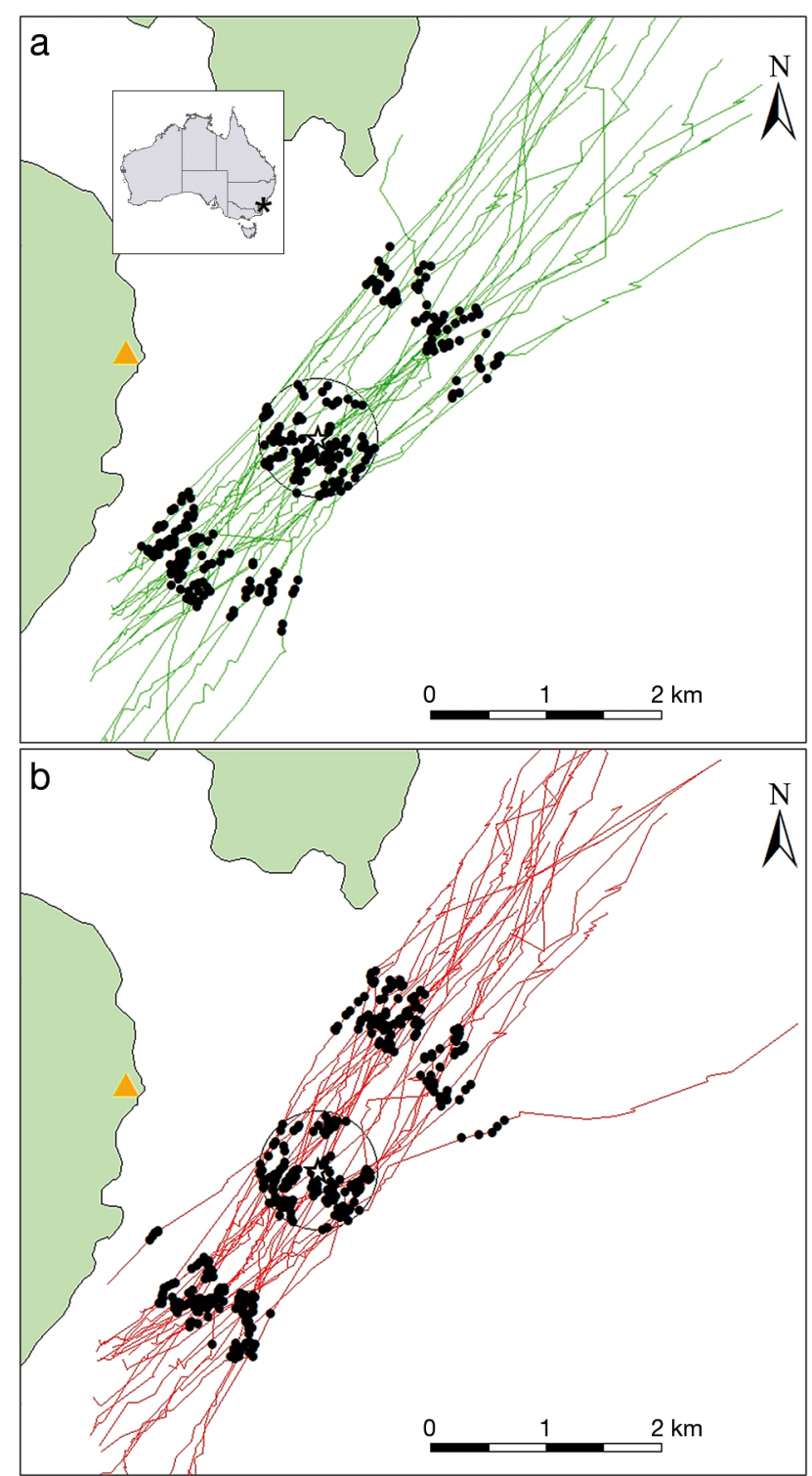

Fig. 1. All humpback whale Megaptera novaeangliae tracks that passed within $500 \mathrm{~m}$ of the whale alarm mooring when it was switched (a) off and (b) on. The triangle represents the location of the theodolite; the alarm is represented by a star and is in the centre of the $500 \mathrm{~m}$ radius (circle) of the likely acoustic detection zone. Each black dot represents a surfacing within each of the measured zones (on approach, within range and beyond the alarm). Surfacings not used in the analysis, i.e. outside the measured zones, have been removed for visual clarity

The direction that whales were heading changed with location $\left(F_{2,702}=7.709, \mathrm{p}<0.05\right)$, but there was no effect of the alarm $\left(F_{1,702}=0.961 \mathrm{p}>0.05\right)$ or any interaction of alarm and location $\left(F_{2,702}=0.501, \mathrm{p}>\right.$ 0.05), suggesting that these differences were due to something other than the alarm, such as topography (Fig. 2a). Whales did not make greater sequential 

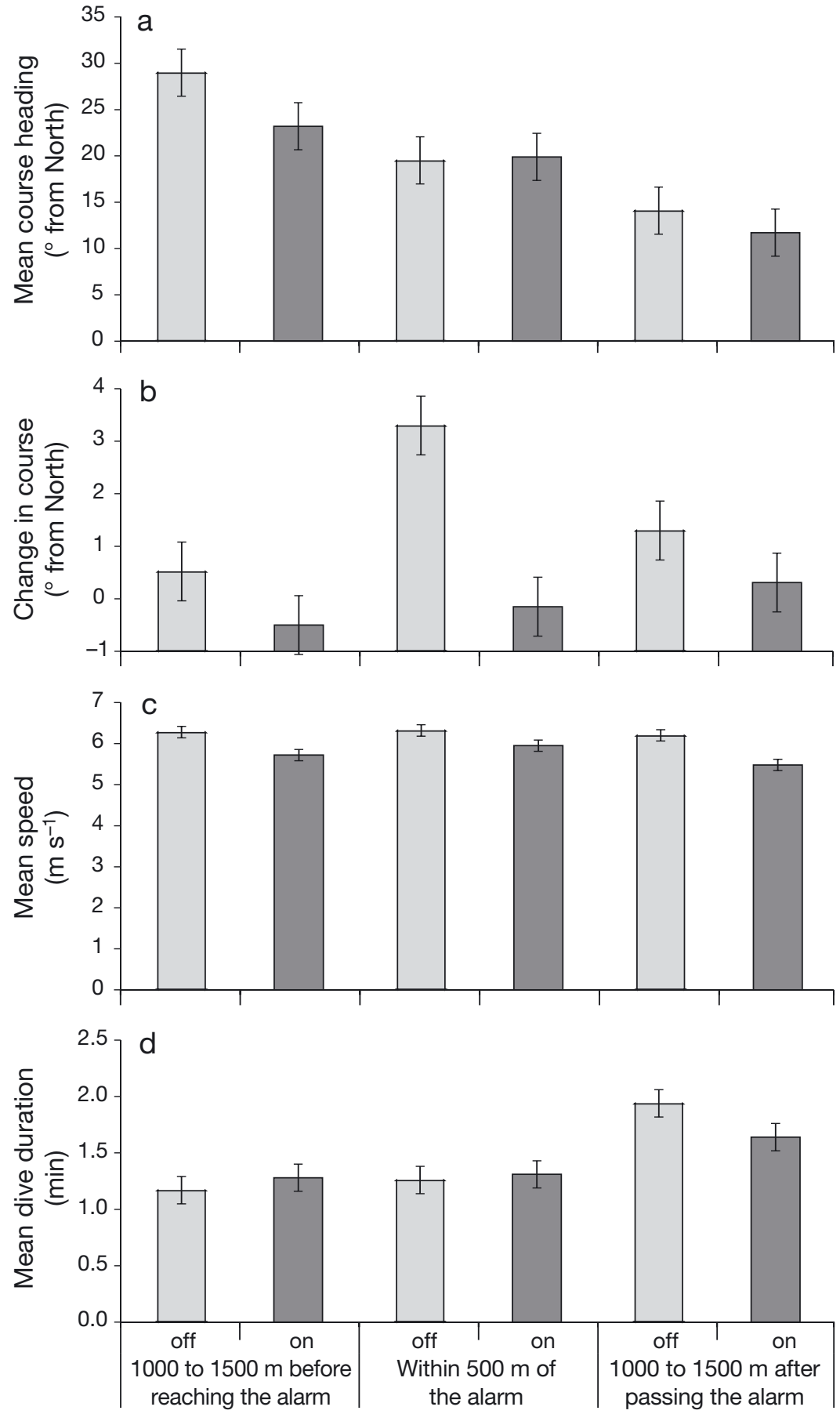

Fig. 2. Variations in (a) mean course heading, (b) mean change in course in degrees from north, (c) mean speed $\left(\mathrm{m} \mathrm{s}^{-1}\right)$ and (d) mean dive duration (min) of migrating humpback whales Megaptera novaeangliae according to whether the alarm was activated (on: dark grey) or not (off: light grey). Responses were evaluated within 3 delineated zones used in the analysis: (1) approaching the alarm but out of hearing range ( $\mathrm{n}=111 \mathrm{off}, 127 \mathrm{on})_{i}$ (2) in the vicinity of the alarm and within hearing range ( $\mathrm{n}=118$ off, $157 \mathrm{on}$ ); (3) beyond the alarm and out of hearing range ( $\mathrm{n}=78$ off, 117 on). Error bars represent standard errors. Statistically significant differences were found only where course was significantly different for proximity to the alarm (but not with respect to alarm status) and where speed was significantly different for alarm status (but not for proximity to the alarm) directional changes in response to the alarm $\left(F_{1,702}=0.224, \mathrm{p}>0.05\right)$, or in response to their location with respect to the alarm $\left(F_{2,702}=0.063, \mathrm{p}>0.05\right.$, Fig. $\left.2 b\right)$.

Mean speed of migrating whales was slower when the alarm was on $\left(F_{1,528}=\right.$ $16.148, \mathrm{p}<0.05)$ irrespective of their distance from the alarm: neither vicinity to the alarm $\left(F_{2,528}=1.550, \mathrm{p}>0.05 ;\right.$ Fig. $\left.2 \mathrm{c}\right)$, nor the interaction term $\left(F_{2,528}=0.551, \mathrm{p}>\right.$ 0.05) was significant. It appears that the decrease in speed was due to factors other than the alarm status.

Mean dive duration did not vary with alarm status $\left(F_{1,702}=0.094, \mathrm{p}>0.05\right)$, and although dive duration differed among the 3 areas $\left(F_{2,702}=4.633, \mathrm{p}<0.05\right)$, again this difference was not due to the alarm (Fig. 2d). Whales dived for longer duration in the area after they has passed the alarm, whether it was on or off.

\section{DISCUSSION}

Whale entanglement is a major issue for fisheries management and conservation agencies in many parts of the world and has a very high public profile for coastal species (Johnson et al. 2005, Moore 2014). The high costs of disentanglement-both in monetary terms and in terms of risk to personneltogether with the low success rate in many instances mean that effective preventative measures are strongly preferred. In this study, we assessed the effectiveness of a widely used commercial acoustic alarm as a deterrent to coastally migrating humpback whales off the east coast of Australia and failed to find any evidence of effective deterrence. Whales did not actively avoid the alarms by altering course upon entering the predicted audible range of the alarm, they did not speed up or slow down when the alarm was audible, and they showed no responses at the surface which might suggest they were more attuned to the presence of the alarm when it was on than when it was off. This was despite in situ measurements confirming that the alarm was function- 
ing as specified. Our results strongly suggest that the alarm is ineffective as a means of reducing the potential for entanglements, at least in the configuration tested. This configuration was, we believe, the one most appropriate for trap and pot lines, for which humpback whales have been identified as being particularly prone to risk of entanglement (Brown et al. 2013).

Whale entanglement is an international problem. In a recent review of mitigation efforts to reduce large whale mortality due to anthropogenic influences, entanglement in fishing gear was found to be the primary cause of death across all species (van der Hoop et al. 2013). Rates of entanglement in some areas of the Northern Hemisphere appear extraordinarily high, with analyses of scar occurrence on whales indicating that $82 \%$ of North Atlantic right whales Eubalaena glacialis and 48 to $57 \%$ of humpback whales in the Gulf of Maine have experienced at least 1 previous entanglement in fishing gear (Robbins \& Mattila 2004, Knowlton et al. 2012). In the Southern Hemisphere, scarring rates are lower but increasing (Meÿer et al. 2011). Exacerbating this problem is the fact that entanglement mortality of most balaenopterids is likely to be underestimated due to under-reporting by fishermen and a low probability of discovery at sea as carcasses sink (Cole et al. 2006). Reporting and discovery is likely to be higher for balaenid whales (e.g. right whales) entangled in coastal waters as their carcasses typically float (Moore et al. 2007), but even balaenid mortality will be underestimated as injured animals can swim many hundreds of kilometers before succumbing (Kemper et al. 2008).

In this study, we examined the performance of a single low-frequency alarm as a deterrent to whale approaches as a means of assessing whether whales would be less likely to approach an active alarm on a mooring. Erbe et al. (2011) assessed the directional propagation of a low-frequency whale alarm nominally transmitting at $3 \mathrm{kHz}$ and $135 \mathrm{~dB}$ (i.e. the same as used in this study). They showed that an approaching mammal would experience signals that varied by up to $18 \mathrm{~dB}$ depending on orientation of the alarm, and it is possible that this could impair deterrent effectiveness. In their study, the actual frequency of the ' $3.0 \mathrm{kHz}$ ' alarm ranged between 2.6 and $2.8 \mathrm{kHz}$. As discussed by McPherson (2011), acoustic alarm manufacturers should quote minimum performance specifications (and possibly maximum) rather than mean specifications, and present meaningful directional propagation attributes. Nevertheless, while technical specifications may vary somewhat from those claimed by manufacturers, in this study we field tested an 'off the shelf' alarm, and found no evidence that there was any form of deterrence in approach to the mooring and alarm, while the alarm was evidently functioning. Fluctuations in audibility are an inherent aspect of acoustic transmission in the marine environment, and masking by natural biotic (e.g. whale calls, snapping shrimp) and abiotic sounds (e.g. wind, waves, rain) (Nystuen \& Farmer 1987, Erbe \& McPherson 2012) as well as anthropogenic noise (e.g. shipping noise, underwater construction; McCarthy \& Miller 2002, Hildebrand 2009) needs to be taken into account when deploying acoustic alarms. Accordingly, to work as an effective deterrent, an acoustic alarm should be audible at distances far enough away from any potential fishing gear that whales can take evasive action under the most adverse ambient noise conditions, rather than under ideal conditions.

The failure of this widely used acoustic alarm to alter the path of migrating Southern Hemisphere humpback whales and thus reduce their probability of becoming entangled in a trap or pot line is disappointing. The tone used in this study was a simple $3 \mathrm{kHz}$ tone of $400 \mathrm{~ms}$ repeated every $5 \mathrm{~s}$. In a recent study, Dunlop et al. (2013) reported clear, unequivocal and repeatable responses by humpback whales to an upswept tone of 2.0 to $2.1 \mathrm{kHz}, 1.5 \mathrm{~s}$ duration, repeated every $8 \mathrm{~s}$. Given the importance of finding effective mitigation strategies to reduce the likelihood of whale entanglement, further trials with more complex acoustic signals, such as an upswept tone, and/or higher density arrays of existing alarms seem worthwhile.

Acknowledgements. This research was made possible through funding from the Department of Environment, Water, Heritage and the Arts, the Australian Marine Mammal Centre, Australian Antarctic Division, the Commonwealth Environment Research Facilities (CERF) programme and the Taronga Conservation Science Initiative. The study was conducted under the auspices of Macquarie University's Animal Ethics Committee Animal Research Authority 2012-016, and Scientific Research permit SL100953 issued by NSW Office of Environment and Heritage to Geoff Ross. Thanks to Dr. Doug Cato, Geoff McPherson and Geoff Ross for extensive consultation on whales, underwater acoustics and wildlife permitting. We thank Maryrose Gulesserian, Eric Kneist (author of VADAR ${ }^{\circledR}$ ) Wayne Reynolds and the Cape Solander Migration Study for facilitating the research, and Andrew Boomer, Andrew Irvine, Andre Steckenreuter and Phil McDowall for assistance in mooring assemblage, deployment and retrieval. The editor Dr. Randall Reeves and 3 referees greatly improved the manuscript with very constructive comments. 


\section{LITERATURE CITED}

Bradford AL, Weller DW, Wade PR, Burdin AM, Brownell RL Jr (2008) Population abundance and growth rate of western gray whales Eschrichtius robustus. Endang Species Res 6:1-14

Brown SL, Reid D, Rogan E (2013) A risk-based approach to rapidly screen vulnerability of cetaceans to impacts from fisheries bycatch. Biol Conserv 168:78-87

> Cassoff RM, Moore KM, McLellan WA, Barco SG, Rotstein DS, Moore MJ (2011) Lethal entanglement in baleen whales. Dis Aquat Org 96:175-185

$>$ Chittleborough R (1965) Dynamics of two populations of the humpback whale, Megaptera novaeangliae (Borowski). Mar Freshw Res 16:33-128

Clark CW, Ellison WT (2004) Potential use of low-frequency sounds by baleen whales for probing the environment: evidence from models and empirical measurements. In: Thomas JA, Moss C, Vater M (eds) Echolocation in bats and dolphins. The University of Chicago Press, Chicago, IL, p 564-582

Cole T, Hartley D, Garron M (2006) Mortality and serious injury determinations for baleen whale stocks along the eastern seaboard of the United States, 2000-2004. Reference Document 06-04. Northeast Fisheries Science Center, Gloucester, MA

> Dawson SM, Northridge S, Waples D, Read AJ (2013) To ping or not to ping: the use of active acoustic devices in mitigating interactions between small cetaceans and gillnet fisheries. Endang Species Res 19:201-221

Dunlop RA, Noad MJ, Cato DH, Kniest E, Miller PJO, Smith JN, Stokes MD (2013) Multivariate analysis of behavioural response experiments in humpback whales (Megaptera novaeangliae). J Exp Biol 216:759-770

Erbe C, McPherson C (2012) Acoustic characterisation of bycatch mitigation pingers on shark control nets in Queensland, Australia. Endang Species Res 19:109-121

Erbe C, McPherson G, Craven A (2011) Acoustic investigation of bycatch mitigation pingers. Project Report 10/21 to Australian Marine Mammal Centre. JASCO Applied Sciences, Brisbane

Gales N, Bannister J, Findlay K, Zerbini A, Donovan G (2011) Report of the Workshop on the Comprehensive Assessment of Southern Hemisphere humpback whales. J Cetacean Res Manag Spec Issue 3:1-50

Green M, Ganassin C, Reid DD (2009) Report into the NSW Shark Meshing (Bather Protection) program: incorporating a review of the existing program and environmental assessment. DPI Fisheries Conservation and Aquaculture Branch, Orange. www.dpi.nsw.gov.au/_data/assets/pdf _file/0008/276029/Report-into-the-NSW-Shark-MeshingProgram.pdf

Groom C, Coughran D (2012) Entanglements of baleen whales off the coast of Western Australia between 1982 and 2010: patterns of occurrence, outcomes and management responses. Pac Conserv Biol 18:203-214

Gulesserian M, Slip D, Heller G, Harcourt R (2011) Modelling the behaviour state of humpback whales Megaptera novaeangliae in response to vessel presence off Sydney, Australia. Endang Species Res 15: 255-264

Harcourt R, Marsh H, Slip D, Chilvers L, Noad M, Dunlop R (in press) Marine mammals, back from the brink? Contemporary conservation issues. In: Stow A, Maclean N, Holwell G (eds) Austral ark: state of wildlife in Aus- tralia and New Zealand. Cambridge University Press, Cambridge

Hildebrand JA (2009) Anthropogenic and natural sources of ambient noise in the ocean. Mar Ecol Prog Ser 395: $5-20$

International Whaling Commission (2011) Report of the workshop on the comprehensive assessment of right whales. IWC SC64/Rep5. International Whaling Commission, Cambridge

Jefferson TA, Curry BE (1996) Acoustic methods of reducing or eliminating marine mammal-fishery interactions: Do they work? Ocean Coastal Manag 31:41-70

Johnson A, Salvador G, Kenney J, Robbins J, Kraus S, Landry S, Clapham P (2005) Fishing gear involved in entanglements of right and humpback whales. Mar Mamm Sci 21:635-645

Kemper C, Coughran D, Warneke R, Pirzl R, Watson M, Gales R, Gibbs S (2008) Southern right whale (Eubalaena australis) mortalities and human interactions in Australia, 1950-2006. J Cetacean Res Manag 10:1-8

Ketten DR (1997) Structure and function in whale ears. Bioacoustics 8:103-135

- Knowlton AR, Hamilton PK, Marx MK, Pettis HM, Kraus SD (2012) Monitoring North Atlantic right whale Eubalaena glacialis entanglement rates: a $30 \mathrm{yr}$ retrospective. Mar Ecol Prog Ser 466:293-302

Lien J, Barney W, Todd S, Seton R, Guzzwell J (1992) Effects of adding sounds to cod traps on the probability of collisions by humpback whales. In: Thomas J, Kastelein R, Supin AY (eds) Marine mammal sensory system. Plenum Press, New York, NY, p 701-708

Lotze HK, Coll M, Magera AM, Ward-Paige C, Airoldi L (2011) Recovery of marine animal populations and ecosystems. Trends Ecol Evol 26:595-605

Magera AM, Flemming JEM, Kaschner K, Christensen LB, Lotze HK (2013) Recovery trends in marine mammal populations. PLoS ONE 8:e77908

> McCarthy E, Miller JH (2002) Is anthropogenic ambient noise in the ocean increasing? J Acoust Soc Am 112:2262

McPherson G (2011) Acoustic methods to mitigate bycatch and depredation by marine mammals on commercial fishing operations in Australian waters: Fishermen's options. Proceedings of ACOUSTICS 2011, Gold Coast, Australia, 2-4 November 2011, p 1-8

> Meÿer MA, Best PB, Anderson-Reade MD, Cliff G, Dudley SFJ, Kirkman SP (2011) Trends and interventions in large whale entanglement along the South African coast. Afr J Mar Sci 33:429-439

Moore MJ (2014) How we all kill whales. ICES J Mar Sci, doi:10.1093/icesjms/fsu008

> Moore MJ, van der Hoop JM (2012) The painful side of trap and fixed net fisheries: chronic entanglement of large whales. J Mar Biol 2012:1-4

Moore MJ, McLellan WA, Pierre-Yves D, Bonde RK, Knowlton AR (2007) Right whale mortality: a message from the dead to the living. In: Kraus SD, Rolland RM (eds) The urban whale. Harvard University Press, Cambridge, MA, p 358-379

Noad MJ, Dunlop RA, Paton D, Cato DH (2011) Absolute and relative abundance estimates of Australian east coast humpback whales (Megaptera novaeangliae). J Cetacean Res Manag Spec Issue 3:243-252

Nystuen JA, Farmer DM (1987) The influence of wind on the underwater sound generated by light rain. J Acoust Soc Am 82:270-274 
Paterson R, Paterson P, Cato DH (1994) The status of humpback whales Megaptera novaeangliae in east Australia thirty years after whaling. Biol Conserv 70:135-142

Pauly D, Watson R, Alder J (2005) Global trends in world fisheries: impacts on marine ecosystems and food security. Philos Trans R Soc Lond B Biol Sci 360:5-12

Reid D, Robbins W, Peddemors VM (2011) Decadal trends in shark catches and effort from the New South Wales, Australia, Shark Meshing Program 1950-2010. Mar Freshw Res 62:676-693

Robbins J, Mattila DK (2004) Estimating humpback whale (Megaptera novaeangliae) entanglement rates on the basis of scar evidence. Final report. Northeast Fisheries

Editorial responsibility: Randall Reeves,

Hudson, Quebec, Canada
Science Center, Woods Hole, MA

van der Hoop JM, Moore MJ, Barco SG, Cole TVN and others (2013) Assessment of management to mitigate anthropogenic effects on large whales. Conserv Biol 27: 121-133

Vang L (2002) Distribution, abundance and biology of Group V humpback whales Megaptera novaeangliae: a review. Queensland Government, Environmental Protection Agency, Brisbane, p 1-20

Weller DW, Bettridge S, Brownell RL Jr, Laake JL and others (2013) Report of the national marine fisheries service gray whale stock identification workshop. NOAA Tech Memo NMFS-SWFSC-507 Springfield, VA

Submitted: March 4, 2014; Accepted: May 20, 2014

Proofs received from author(s): July 15, 2014 